\title{
Online Engagement Gaps among Adult Learners of Higher Education in the Post-Covid-19-Era
}

\author{
Mei Yuan Law \\ Correspondence: Mei Yuan Law, Cluster of Education and Social Sciences, Open University Malaysia, Kuala Lumpur, \\ Malaysia.
}

Received: January 5, 2021

Accepted: February 16, 2022

Online Published: February 17, 2022

doi:10.11114/jets.v10i3.5489

URL: https://doi.org/10.11114/jets.v10i3.5489

\begin{abstract}
The purpose of this study is to discover the factors behind the online engagement gaps among adult learners in their postgraduate educational studies in the post-COVID-19 era. The qualitative approach was conducted on postgraduate adult students from an open university in Malaysia, using interviews, observations, and document analysis techniques. The findings of this study show three main themes of factors that influence the online engagement gaps among adult learners; personal conditions, institutional conditions, and external digital technology conditions. The small sample size only involved participants from a similar postgraduate course. The results are accurate only for this group of participants, limiting the transferability of the findings. There is no rich data to affirm on the internet connection of all students since the data can only be collected via interviews of participants and observation of participative students during live sessions. The study revealed that the factors influencing online engagement among adult learners could be helpful for future conceptual framework development and ensure continued success in online learning engagement in the post-COVID-19 era.
\end{abstract}

Keywords: online engagement gaps, online engagement, higher education, adult learners, postgraduate student online engagement

\section{Introduction}

\subsection{Background of the Study}

The digitalization of higher education is inevitable in Industrial Revolution 4.0. Learning has emerged with the tremendous development of computer technology, the internet, and multimedia technology. Pathak (2016) emphasized that universities will not operate in their current face-to-face campus experience for the future learning landscape and imply online learning components. The emergence of the COVID-19 pandemic has certainly caused unprecedented changes in higher education institutions (Chung, Noor \& Mathew, 2020), forcing both public and private higher education institutions in Malaysia to adapt to online and virtual learning content, switching from traditional ones to face-to-face delivery or blended learning to fully online learning. The technological shift reshaped how students engage with their educators via synchronous and asynchronous communication (Law, 2021). With online learning being continued in the post-COVID-19 era, it is undeniable that online learning is deemed the best solution to ensure higher education continuity.

However, these new online practices may have some setbacks, such as lack of human touches like sensing students' incomprehension via facial expressions, making small jokes to enlighten mood in a physical class, face-to-face engagement and interaction. More often than ever, students' lack of student engagement when participating in online learning is one of the most concerning issues in online learning systems (Purarjomandlangrudi and Chen, 2020). It is challenging for educators to grasp student engagement in the online learning environment, especially emotional engagement due to the lack of communication. Undeniably, the emergence of the online learning environment has changed educational learning in Malaysia's higher education institutions, in which institutions have to focus on online delivery (Law, 2021). The primary problem started when educators and students needed to find the equilibrium in online engagement for institutions that adopted face-to-face or blended learning models to ensure continual and practical learning. Some students will thrive, while others become demotivated and disengaged. Martin and Bolliger (2018) advocated the crucial role of student engagement in students learning, especially in online settings. Exploring the different factors influencing adult learners' online engagement is crucial for success in online learning. 


\subsection{Research Objective and Research Questions}

Given the changes in learning mode, the primary purpose of this case study is to identify the factors behind the online engagement gaps among adult learners in their postgraduate educational studies in the post-COVID-19 era. While considering the complexity of online learning education is novel, understanding adult students' engagement is worth pursuing. The case study sought to understand students' online engagement within the course commencement semester timeline. There are multiple social realities about the factors influencing students to participate in online engagement.

It is essential to capture the meanings and experiences of the participants who participated in the course program, which the reality could not be easily defined by the researcher alone. Through the students' voices and experiences, the research will discover the factors which cause the gaps in the online engagement of adult learners and, more importantly, can serve as a conceptual framework for future research purposes to increase the engagement of adult learners in online learning. In order to answer the research purpose, the research study is guided by two overarching research questions:

1. What factors account for the gaps in engagement levels among adult learners?

2. How do these factors influence the continuity of online engagement among adult learners?

\section{Literature Review}

\subsection{Student Engagement in Online Learning}

With the constant improvement and development of online learning, many scholars and researchers have actively explored student engagement in online learning to obtain rich theoretical and practical results. Wong and Chong (2018) defined online engagement as the collection of active learning, participation and involvement in educational activities, emotional support, and communication with peers and educators. Moreover, Martin and Bolliger (2018) stated three types of engagement: learner-to-learner engagement, learner-content engagement, and learner-instructor engagement, while claiming that engagement and interaction are used interchangeably. In a more comprehensive view, student engagement is the state of psychology, cognitive, emotional, and behavioral reactions to achieve the desired learning outcome (Gunuc \& Kuzu, 2015).

\subsection{Research on Influencing Factors}

\subsubsection{Social and Emotional Support in Online Environment}

The previous research and findings show that social interaction and emotional support are arguably the most crucial factors for online learning engagement. Efforts are vital to stimulate activities that introduce and enhance engagement with peers to prevent students from potential isolation or boredom in the online learning settings (Martin, Wang \& Sadaf, 2018). Martin and Bolliger (2018) quantitative study mentioned the value of learner-to-learner interaction in online learning, which leads to student engagement in their learning journey. It is essential to create a sense of belongingness and community among the learners in online learning (Stone \& O'Shea, 2019; Kumar \& Heathcock, 2016; Buck, 2016) significantly impacts online students' learning engagement and experiences (Buck, 2016; O'Shea, Stone \& Delahunty, 2015). Phirangee and Malec (2017) in-depth semi-structured interviews discovered that fostering a strong sense of community among students in an online setting can reduce isolation and disconnection. In addition, the employment of icebreaker activities enable interactivity and creating meaningful experiences for students (Watkins, 2014).

The utilization of social media encourages students to participate and enhance online engagement via social interaction (Everson, Gundlach, \& Miller, 2013). The community can be fostered through informal student interaction and engagement via social media and study groups (O'Shea et al., 2015). Law (2021) mixed method study advocated the importance of forming online study groups outside online classes, in which students can provide motivation and encouragement during the learning process. The researcher indicated the effectiveness of live class sessions provided synchronous communication and established a sense of community among the peers while interacting. Banna, Lin, Stewart \& Fialkowski (2015) qualitative study added suggestions in using videoconferencing or chatting in synchronous activities and discussion boards for asynchronous activities, enhancing learner-to-learner interaction.

Wang and Sui (2020) added that emotional and cognitive engagement among students is correlated to the self-regulated learning process. The educators are advised to engage students emotionally for continual success in online learning. Moreover, online academic supports have become paramount to student engagement in online learning (Huwiler, 2015). Instructors should provide students with the opportunity to have ample student-instructor interaction. Law (2021) and King (2014) emphasized that consistent interaction with students at the individual or group levels help set academic expectations among students. Martin and Ertzberger (2015) pointed out providing reflection opportunities to stimulate meaningful learning as students share ideas. King (2014) agreed on the constant collaboration between students and instructors in online learning to increase online student engagement. Farrell and Brunton (2020) qualitative case study 
discovered that instructors' social support in synchronous online sessions and asynchronous discussion forums encouraged engagement among students and instructors. Redmond, Heffernan, Abawi, Brown and Henderson (2018) and Douglas, Mather, Murray, Earwaker, James, Pittaway, Robards and Salter (2015) emphasized the expectation for instructors to be the facilitator of conversation to stimulate social engagement. The instructor's presence and behavior play a crucial role in students' online engagement (Muir, Milthorpe, Stone, Dyment, Freeman \& Hopwood, 2019; Martin \& Bolliger, 2018).

\subsubsection{Design of Online Content and Technological Tools}

Chen, Bastedo and Howard (2018) indicated that high-quality learning content with well-specified and organized learning objectives is essential in student learning engagement. The design and layout of the online learning platforms, including the (LMS) Learning Management System and the digital content provided, play a significant role in student engagement (Law, 2021; Deschaine \& Whale, 2017). Thomas and Thorpe (2019) literature review study indicated the significance of online forums structure and the quality of interaction with the content. Nevertheless, Dushkevych, Barabashchuk and Hutsuliak (2020) quantitative study indicated that imperfection online learning platforms are the drawback of virtual online engagement for learners. The platform and media employed for communication and connection should provide students with the opportunity to better represent themselves in an online environment (Purarjomandlangrudi \& Chen, 2020).

In addition, Muir et al. (2019) mentioned that attractive course designs that stimulate interest positively affect student engagement. Studies also found that organized activities with various learning resources and content types contribute to online students' engagement (Liu \& Zhang, 2020; Lee \& Hannafin, 2016; Douglas et al., 2015). Synchronous and asynchronous delivery are practical options that help students to access online content for critical interaction (Buck, 2016; Banna et al., 2015). Deschaine and Whale (2017) emphasized polling application during synchronous online learning sessions at multiple points, ensuring students are engaged and attentive. However, the course design structure should provide alternatives for the student in accessing past synchronous content via recorded videos, considering the possibility of students' with an unstable, poor or low bandwidth internet connection (Law, 2021; Deschaine \& Whale, 2017). Law (2021) and Dushkevych et al. (2020) also highlighted poor internet network connection as one of the issues which interfere with learners' engagement in online learning.

Banna et al. (2015) suggested that online instructors invest immense effort and time searching and providing extensive scholarly reading materials. The authors added instructors to design interactive instructional materials and well-thought assessments, encouraging learner-to-content engagement. Buck (2016) and Britt (2015) supported the suggestions by adding real-world projects application, which shows students the authenticity and comparative examples of the course content during the content engagement. Preparing content more expansively enhances student engagement during online instructional sessions (Deschaine \& Whale, 2017). Furthermore, Kumar and Heathcock (2016) study focused on an online doctoral program indicated the importance of providing appropriate and sufficient instruction to meet the needs of the students in online learning for easy engagement to comprehensive online learning resources. Banna et al. (2015) also recommended using internet applications like the Google application package or audio-video technology to improve online engagement. However, Stone and O'Shea (2019) highlighted that inappropriate online course design and delivery could negatively impact online student engagement.

\subsubsection{Readiness and Preparedness for Online Study}

Students' self-efficacy plays a vital role in influencing online engagement during online learning. Positive psychology and mindful interventions are the keys to enhancing students' engagement (Hammill, Nguyen \& Henderson, 2020). Farrell and Brunton (2020) qualitative study and Kahu, Picton and Nelson (2019) weekly semi-structured interviews indicated that student self-efficacy influenced interest and behavioural engagement with learning. Purarjomandlangrudi and Chen (2020) quantitative study also confirmed that students' attitudes towards online learning strongly influence their engagement online. Chung et al. (2020) found out that students rarely engage in face-to-face lessons due to social stigma and possess a low level of online communication self-efficacy, affecting students' online learning readiness and preparedness. As online learning is facilitated through digital technology, media and the internet, online students must have competent digital skills to engage with online courses (Brown, Hughes, Keppell, Hard \& Smith, 2015). Undeniably, new students struggle with the online learning environment, requiring time and support to sufficiently orientate online engagement (Stone \& O'Shea, 2019). In addition, Paul (2018) also discovered that students' motivation and self-confidence were the main factors influencing online learning engagement and online discussion.

\subsubsection{Work and Life Commitments}

Deschaine and Whale (2017) discovered that work distractions and noise disturbance in students' environments would lead to difficulty in synchronous engagement, especially when students participate from home. Many of these distractions are seldom found in face-to-face environments. Time management is a decisive factor in determining 
students' engagement in online learning (Farrell and Brunton, 2020). Adult learners need to balance the competing demands in life and work while finding sufficient time to engage in online studies. Many online students struggle to follow and engage in studies regularly due to the balance between work, family and study (Buck, 2016; Brown et al., 2015). Stone and O'Shea (2019) and Brown et al. (2015) highlighted that the underlying pressure and stress from the demanding commitments would interfere and affect students' engagement in online studies.

In summary, the literature highlights the importance of viewing online student engagement through the lens of social and emotional support, the design of online content and technological tools, the readiness and preparedness for online study, and work and life commitments influences. However, there are gaps in the research on the experiences of online students in higher education. The majority of the relevant literature focused on the young, undergraduate, full-time students based in overseas universities outside Malaysia (Dushkevych et al.; 2020, Farrell \& Brunton, 2020; Kahu et al., 2019; Martin \& Bolliger, 2018, O’Shea et al., 2015; Brown et al., 2015; King, 2014). A few pieces of works of literature focused on adult learners but in a different context, in which the universities are structured for online learning delivery (Martin \& Bolliger, 2018; Deschaine and Whale, 2017; Buck, 2016; Brown et al., 2015). Research that focuses on postgraduate studies emphasized structured online delivery (Stone \& O'Shea, 2019; Kumar \& Heathcock, 2016; O'Shea et al., 2015). Furthermore, most literature is conducted in an environment during the COVID-19 crisis (Law, 2021; Farrell \& Brunton, 2020; Dushkevych et al. (2020). The factors influencing student engagement could differ from those in online learning in a post-COVID-19 environment. Therefore, this research will enrich the understanding of the underlying factors that influences adult learners' engagement in a post-COVID-19 era.

\section{Methodology}

\subsection{Research Method}

A qualitative study grounded in the constructivist paradigm was designed to explore online student engagement experiences in online learning settings in a post-COVID-19 era. Three data collection methods are employed for the qualitative case study; interview, observation and document analysis. A detailed explanation of the data collection techniques will be introduced later in this report.

\subsection{Sample Selection}

The participants involved in the research study are from a private open university from Malaysia. The study participants came from a heterogeneous composition of students registered in the 2021 intake from different units in a doctoral degree course. A purposive sampling technique, also known as a non-probability sampling technique, is used to capture a wide range of perspectives relating to the topic of the research study. The technique is also known as heterogeneous purposive sampling, enabling the study to focus on diverse cases from different units enrolled by adult students from different working and learning experience backgrounds.

Several reasons support applying the purposive sampling method to select the participants for the research study. Different units of the same postgraduate course deploy different teaching approaches, and learning techniques facilitated by multiple instructors might influence students' engagement during online learning, providing a broader understanding of how the learning materials and instructions are conducted. Besides, a heterogeneous sample will provide a wider variety of results in the online engagement activities as each individual are experiencing different scenario and have personal preferences in online learning. Thirdly, the students enrolled come from different states in Malaysia and other countries. The diversity will enrich the data understanding further.

Selecting the sample size was challenging as reaching out to the respective targeted students was an issue. The target students' availability and willingness to participate in the study are limited due to time and stable internet connectivity. With much effort, invitations were sent to all targeted students of two different units, with a consent letter included to inform them of the purpose of their participation in the research. They were invited to participate in interviews via online video interviews or voice calls. A total of fifteen students agreed to take part in the interview.

\subsection{Data Collection Techniques}

As mentioned, three different data collection techniques were employed for the case study; interview method, observation and document analysis. There are three instruments used in this study-a researcher-developed Interview Protocol, a researcher-developed Observation Protocol checklist and a simple List of Texts: Document Analysis was used to guide forum engagement and interaction document analysis.

During the preparation stage, the interview guide and procedures were pilot-tested with two research student pilot samples from another university to ensure that the interview questions were easy to comprehend. The students were interviewed with the prepared interview questions and then asked to evaluate and paraphrase the meanings of the interview questions to ensure that the meaning of the interview questions was consistent with the research topic. In addition, the students were asked to review the phrases of the interview questions, which is revised until all two students 
interpreted the meaning in a completely similar way. Moreover, the observation protocol questions were designed with assistance from two other researchers to determine the ease of understanding and appropriateness of the criteria created. Lastly, the researcher created an essential list of texts to aid document analysis in the discussion forum to ensure reliable results. While preparing the research approaches, a formal email was sent to the program director of EdD for permission and consent to conduct qualitative research for units under this program.

\subsection{Data Collection Procedure}

\subsubsection{Interview}

Upon the confirmation of participants to join the respective scheduled online interview sessions, the interview questions were shared a week before the actual interview session. The interviews were successfully executed within a week's timeframe. All the interview data were collected through online video and voice interviews via Google Meet, which took approximately 25 minutes - 35 minutes to gather adequate information. The open-ended interview questions allowed participants to convey and demonstrate their thoughts and experiences in their own words.

\subsubsection{Observation}

The participatory observation method is adopted throughout the eight weeks of class observation on the targeted learning subjects. Each subject class was observed weekly, totaling eight different sessions per subject being observed until the constant pattern and data saturation are met., The researcher becomes integrated into the participants' environment while establishing rapport with the participants. The participatory observation method provided the most natural setting for the participants to engage during online lessons without knowing being observed, which will reduce the likelihood of modification of behavior with prior knowledge being observed.

\subsubsection{Document Analysis}

Document analysis is a social research method and is considered an essential research tool for this research study. Since the interview questions of the research study partly covered online forum discussion and engagement, the document analysis of the forum discussions is an invaluable part of the triangulation of data in a later stage. In any research, it is vital to seek convergence and corroboration in the data collected to provide the reliability and validity of the data.

\subsection{Data Analysis}

\subsubsection{Interview and Observation}

The content analysis method is chosen to analyze the documented information in texts and media. The interviews were transcribed while listening to the interview recordings several times. The repeating process of listening to every single interview multiple times to verify the words and phrases used by the participants. Confirmation was made with each participant to ensure the verbatim were transcribed as portrayed by the participants. The deductive coding approach is applied, in which concept-driven coding is considered the suitable approach for this research study. The coding process started with the line-by-line, in which important points were highlighted and given respective codes. The process was repeated for the remaining transcription, followed by categorization steps in which the codes are categorized into subcategories, categories and themes. A similar analysis and coding process are repeated for all eight observation sessions' data. After that, two inter-rater who served as $\mathrm{PhD}$ students were invited to code the verbatim to ensure the validity and reliability of the findings. The differences and disagreements in data categorization were discussed and concluded reasonably for the final results. The reliability of the inter-rater is calculated based on the percent agreement method to ensure the level of agreement between the raters. The result indicated an $80 \%$ agreement score.

\subsubsection{Document Analysis}

The document analysis refers to analyzing the online discussion forum of the two subjects involved in this research study. The analysis of the forum discussions was carried out for different segments of the discussion topics. However, the document analysis did not involve any inter-rate to validate the coding as no external users can access the system without permission.

\section{Results}

\subsection{Personal Conditions}

The data retrieved from the interviews and observation of the live learning sessions showed a solid and comprehensive understanding of how personal conditions affect and influence individual online learning engagement as an adult student. The most dominant category from the findings is the personality of the students. The observation and document analysis of the forum discussion activities have determined that each student's personality drives their involvement and active engagement with peers, tutors, and course-related activities or discussions. The findings are supported by various claims from the participants during the interviews. Only three participants claimed that they are extroverted learners. In 
contrast, other participants claimed that they are passive and introverted learners who prefer to maintain low profile conditions and interact very little. They feel rather uncomfortable talking in a group.

Self-efficacy and motivational level are vital in determining their online engagement, as observed from live learning sessions. Ten students from the interview expressed that their inconsistent online engagement with their peers and tutors are mainly due to self-efficacy. They claimed to doubt their own ability to contribute practical knowledge to others. On the other hand, five students claimed that self-efficacy is essential to promote constant accomplishment and engagement during online learning. Furthermore, two-third of the total number of participants claimed that interacting and communicating with peers via social media such as WhatsApp did boost the motivational level to engage in studies. Three participants mentioned that staying motivated through beliefs and meditation can support individual attitudes in engaging and interacting during online studies. Students then concluded that holding strong philosophical beliefs help motivate in achieving learning goals and overcoming obstacles.

Twelve participants who served as full-time working adults expressed the pressure and frustration of life and work, which occasionally affects online learning engagement. As a working adult, the juggles between life, work and study have challenged many students. Two students pointed out, "It is challenging for me to focus when I am studying at home. My kids are making noises which makes it hard for me to concentrate," and "Since we now work from home, it is a distraction to my studies". During the observations, many students in the live session chat expressed the effort to balance their studies. In order to maintain their engagement and interaction in synchronous and asynchronous learning, time management and discipline have been their main pillars. Moreover, all participants expressed during the interview that they should be responsible learners, especially as an adult. Thus, prior reading and understanding learning topics is essential for online learning engagement.

All participants of the interviews expressed their level of digital literacy as desirable during online engagement and interaction. The experiences and digital knowledge have undoubtedly been used for their current online study. However, during the observation, three students encounter challenges in using and understanding the functionality of the digital library or finding certain course content. Another major factor being highlighted by the participants is digital fatigue, which highly influences their online engagement. Due to the new norm in which office workers are shifted to online mode, they have to spend extensive time in front of digital devices for their studies. All students showed concern that long-term exposure to digital screens can be tiring for their eyes and mental state during the interview sessions.

\subsection{Institutional Conditions}

The educator's support is indicated as one of the dominant factors influencing students' online engagement from the data collected. The observation data showed that the tutors' constant social and emotional support and willingness to assist promote students' engagement and interaction during live learning sessions. Tutors displayed constant assistance and responsiveness to students in assignments and other course content-related topics. Ten participants indicated that the tutor was encouraging during the interviews, which helped build strong students' self-efficacy. Also, all students claimed the tutors took the effort to record every live session for future references and playback, considering the possibility of students missing out on particular sessions. Students stated that the discussions help to set their academic expectations. Nevertheless, two participants did bring up the concern about being organized in providing clear instructions and expectations for the assignments at the beginning of the semester and not postponing the discussions dates, which causes insecurities among students.

The observation showed that teaching strategy plays a vital role in stimulating engagement among students in online learning. The tutors used creative and engaging methods during a live interaction from the observation. Tutors broke up the discussions into smaller topics and subtopics to organize online asynchronous discussions during forum discussions. Ten participants revealed that the tutors highly engage during live sessions by generating fun discussion sessions together. Students indicated, "I love to attend tutorial sessions as my tutor is a humorous person. He loves to use examples that are funny yet relatable to topic discussions," and "Quizzes are fun, as we get to discuss and debate what are the answers". Other students indicated the use of Breakout Room on specific live sessions for students to engage and discuss topics in groups. However, four participants brought up the tutor being a little unorganized in time management during the interview, especially during the Breakout Room sessions, which should be improved.

The data retrieved from the interviews, observations, and forum analysis showed that peer's interaction influences each student's engagement. Peer's interaction creates an engaging atmosphere in which students feel the social presence of each individual. It is discovered that more students engage during a live session. As for asynchronous interaction, less than ten students remain active in forum discussions, in which the interactivity rate is lower than live sessions. Twelve participants emphasized the significant impact of bringing a sense of belongingness and community towards their learning engagement during the interview. The constant group discussions have helped them improve their participation and online engagement by creating a study group in WhatsApp. The social and emotional interaction between peers 
effectively stimulates online learning engagement. Two students brought up the idea of having ice-breaking sessions to reduce embarrassment and discomfort during an online engagement, promoting engagement in a relaxed environment.

The data analysis illustrated the course design structure as one of the factors regulating student engagement in online learning. Thirteen participants indicated the flexibility to discuss and choose assignment topics to work on. Students claimed that the tutor provided real-world examples when discussing the course content, which expanded their discussions during online sessions. Although the students are satisfied with the instructional materials provided, they have shown their concern about the structure of the assignments. The assignment workload design does determine students' engagement as students claimed that some subjects might require more work than others. Students also affirmed that it is based on individual preferences for different subjects. Nevertheless, students indicated that live sessions should be conducted in a shorter time frame and more time for reading external materials and doing assignments, considering all registered students are working adults. Overall, students mentioned that they were satisfied with the learning resources and content provided.

The data analysis results discovered that most students are satisfied with the institutions' learning management system (LMS). Many found the system user-friendly and easy to navigate while searching for particular information on the platform. Both local and international students suggested using English as the primary language for the announcements in the LMS. As the online forum is used mainly for asynchronous discussions regarding the learning content, students displayed their concerns on the design of the online forum. Twelve participants from the interview indicated the structure of the discussion thread as confusing and unstructured, resulting in a lack of interest in joining forum discussions. Additionally, students asserted personal preferences in different topic discussions as one of the reasons for the inconsistencies in forum engagement. The students, however, claimed that the tutors were very responsive in the forum discussions and provided compelling support in topic analysis and consultations.

\subsection{External Digital Technology Conditions}

Students advocated that the internet is the primary determinate for online engagement and interaction from the data collected in interviews. Without stable internet connectivity, the experience of online learning and engagement is highly affected. One participant from a rural area stated, "It is challenging for me to have a good reception here, so I can only rewatch the recorded live sessions and mostly failed to join the classes due to weak internet connection in my area". From the observations, internet stability is an issue for the students and tutors. Occasionally, the tutor will be faced internet disconnection or connection buffer during live class sessions. Two students had to refresh or rejoin the class sessions due to internet interference.

In addition, twelve participants expressed appreciation and acceptance of Google Meet as the primary application for online synchronous learning. Participants claimed that the application is easy to use, in which the observation results can support the claim. The majority of the students also showed positive preferences in the poling system, encouraging dynamic interactivity in maintaining students' attention. However, three participants brought up some drawbacks of the Google Meet functionality access as a student. For example, one of the participants mentioned, "I cannot mute my peers' microphone when they have it on when others are talking. It had to be executed on the tutors' end".

\section{Discussion and Conclusion}

\subsection{Personal Conditions}

In the current study, students displayed the personality of every individual as one of the factors, which drive their involvement and active engagement in online learning. The results showed students' openness in engaging with their peers and tutors in both synchronous and asynchronous engagement while a number displayed otherwise. Each individual's extroversion and introversion personality depicts the student's involvement in online engagement. Personality factor was not discussed in the literature reviewed, providing another avenue for research to further understand how personality traits affect online engagement among adult students.

The results displayed similarities to the findings from Chung et al. (2020), in which the readiness and preparedness to online learning are being affected. Students indicated self-efficacy and motivational level as the elements which influence their online engagement for their studies. The findings showed that the lack of online engagement is due to self-efficacy as they doubted their ability to contribute rich conversation with others. On the other hand, the result also exhibited students' positive attitude and claimed self-efficacy to guide their accomplishment in learning tasks and engagement in online learning, which comprehended with the study findings of Hammill et al. (2020), Farrell and Brunton (2020), Purarjomandlangrudi and Chen (2020), and Kahu et al. (2019). Also, students specified that having a robust motivational level and self-confidence is essential for continual engagement and interaction in online studies. The results proved similar findings to Paul (2018) study.

Students indicated that balancing life, work, and study has been challenging to keep up with the studying schedule. 
Many claimed that the new work-from-home norm had caused unwanted distractions and disturbance towards their studies. The findings correspond to the study of Deschaine and Whale (2017) that students faced difficulties in synchronous engagement when participating at home. The students' claims on facing troubles in balancing between work and studies engagement have reflected on the findings of Stone and O'Shea (2019), Buck (2016) and Brown et al. (2015). Some students even described time management and discipline as the main pillars supporting their engagement and interaction in synchronous and asynchronous learning, just as Farrell and Brunton (2020) mentioned.

The current findings reflect that most students are comfortable using the university's digital technology and claimed to be competent in their digital skills, indicating similarities to Brown et al. (2015) findings. It is mainly due to the year-long exposure to the new digital norm after the Covid-19 outbreak. Even though the students highlighted the struggles in using the digital library or searching for learning materials, they claimed that self-exploration and learning from peers' help orientate their online engagement, which comprehends with Stone and O'Shea (2019) study. Besides, the results acquired from the current study show that students have suffered from digital fatigue and have influenced their online engagement activities. Students displayed tiredness after long hours of digital exposure in work. Having to strain their eyes and mental state further in online studies has reduced the possibility of students engaging in online learning activities. However, this issue is not discussed in the literature review, which opens up another direction for further research in this area.

\subsection{Institutional Conditions}

The current findings display the crucial role of educator's support in promoting online engagement among students. Students mentioned the tutors' effort in providing constant support in the aspect of social, emotional and academic support. Students are pleased with their tutors' social and emotional support, which motivated and encouraged continual success in online learning. The results reflected the findings of Wang and Sui (2020) on emotional support as well as Farrell and Brunton (2020) social support discovery. The recorded live sessions are seen as substantial support for many students as they can refer back to any information acknowledged during the synchronous learning. The findings of the academic supports from tutors are seen as crucial for students' engagement in online learning, which indicated a resemblance to Huwiler (2015) study. The academic support via constant interaction in learning materials and assignment related discussions help students to set their academic expectations, which correspond to findings from Law (2021) and King (2014). However, students raised the tutors' trouble for being less organized and time-efficient in providing assignment instructions at an early stage of the course should be considered for future improvement.

The current study also says that teaching strategy plays a determining role in students' engagement. As mentioned by Muir et al. (2019) and Martin and Bolliger (2018), the instructors' presence and behavior play a role in facilitating students' online engagement. The results indicated that students are excited to join the live sessions, mainly is related to the tutor's behavior which creates a sense of community and social presence. Using humor and creative engagement stimulates students' excitement to engage. Interesting engagement methods promote constant collaboration in the live learning sessions, also mentioned in King (2014) findings. Apart from that, the use of quizzes and Breakout Room discussions from time to time provided opportunities for students to reflect and discuss topics as they share ideas. The findings display similarity to Martin and Ertzberger (2016) discovery. From the study, it can be concluded that tutors play a significant role in facilitating the conversation and engagement during live sessions, just as suggested by Redmond et al. (2018) and Douglas et al. (2015).

The current study reflects that peer's interaction influences students' online engagement activities. The study indicated that learner and learner interaction has developed a strong sense of community and belongingness and reduces isolation, as Phirangee and Malec (2017) mentioned. As displayed in the findings, the students used Google Meet for video teaching and chatting while being involved in forum discussion regularly, indicating similarities to Banna et al. (2015) suggestions. Results also specified that live learning sessions are the most effective studying community and environment that foster the sense of community through the interaction in synchronous communication with peers, which comprehends with Law (2021) study. By putting the findings together, they do correspond to Law (2021), O'Shea et al. (2015), and Everson et al. (2013) studies in which they showcased the formation of an external WhatsApp study group is a way to improve students' participation in online engagement. In addition to the findings, students made similar suggestions as Watkins (2014) on the employment of ice-breaking sessions, increasing the interactivity and reducing discomfort during an engagement.

Next, the results show how course design structure regulates and affects students' engagement in online learning. This finding indicated Buck (2016) and Britt (2015) suggestions. Students advocated applying real-world projects in the course content discussions, which enrich the engagement during online instructional sessions, just as Deschaine and Whale (2017) mentioned. Furthermore, the results show similarity to Kumar and Heathcock (2016) study, in which students are supported with sufficient instructional materials to meet the needs of students for online engagement. 
However, students raised the concern on the imbalance distribution of assignment workloads for different course units. They further added that the institution should consider shortening the duration of live sessions to have more time to complete the assigned tasks. The incidents have echoed the concerns highlighted by Stone and O'Shea (2019) on inappropriate online course design and delivery which would negatively impact students' online engagement.

On the learning management system (LMS) aspect, the results acquired from the current study show that students are overall satisfied with the navigation of the LMS system during learning engagement. The results resemble the studies of Law (2021) and Deschaine and Whale (2017). Although students mentioned the language preferences used, they claimed that the digital learning content is sufficient and easy to access. Nevertheless, the results indicated their dissatisfaction with the forum design layout, which they found the discussion thread unorganized, thus reducing their interest in interacting. This finding demonstrates similarity to Thomas and Thorpe (2019) study. Other students stated that their involvement in forum discussions depends on the type of topic discussion raised. Some declared that the repetitive topic discussion structure also significantly reduced their engagement over time. The students' claims reflected the concern raised by Dushkevych et al. (2020) on the possible drawbacks of online engagement due to an imperfect learning platform.

\subsection{External Digital Technology Conditions}

The result of the current study show internet is a critical element in online learning. The experience of online learning engagement is highly dependent on the internet connection, especially for synchronous learning sessions. Students indicated the trouble and frustration of dealing with a poor internet connection, especially in rural areas. The results have proven that students and tutors experienced internet problems during live sessions, causing unnecessary disturbance and inconvenience during the teaching and learning sessions. The findings comprehend Law (2021) and Dushkevych et al. (2020) research studies. The poor internet connection has been one issue that interferes with the learners' engagement in online synchronous learning.

The targeted institution has implemented Google Meet as the primary application for online synchronous learning from the research findings. The students are pleased with the technology application. The majority claimed to like the interactive and engaging way of learning through the polling system, according to Deschaine and Whale (2017) study. The application of the polling system encouraged dynamic interactivity among students during the synchronous learning sessions. Students addressed certain aspects, such as 'Breakout Rooms' function, and microphone muting options should be improved in the execution. Overall, the institution approach shows similarity to Banna et al. (2015) recommendation in using Google application to improve online engagement among learners.

\subsection{Limitations of the Study}

The case study involved only a sample size of fifteen participants, which only involved students from the same postgraduate course. The results are accurate only for this group of participants, limiting the transferability of the findings. Besides, the study only focused on a single social science course. These limit the ability to make a broader generalization from the results. In addition, there is no rich data to affirm on the internet connection of all students since the data can only be collected via interviews of participants and observations on participative students during live sessions. The findings of this study were based on the assumption that the students responded honestly during interviews and had no behavioral bias during the observation period. Nevertheless, the findings are still significant in helping stakeholders to understand the factors influencing online engagement among adult learners, which could be helpful for future conceptual framework development and ensure continued success in online learning engagement of higher education institutions.

\subsection{Recommendation}

More research should replicate by using a different population. Researchers can expand towards postgraduate STEM courses. Therefore, future studies should conduct qualitative and quantitative studies on the research topic in the broader population to generalize data. Besides, more studies should focus on the relationship between students' personalities and online engagement as there are limited empirical studies available for direct support. In addition, future studies should focus on the relationship between digital fatigue and the influence on adult students' online engagement as there is still a lack of research focus and literature in this area.

\subsection{Conclusion}

The study results indicated that personal conditions, institutional conditions and external digital technology conditions had personal effects on students' online engagement. It was found that these elements were all related to the gaps in students' engagement in online learning. This study contributed to practice fields by exploring students' experiences towards online learning from different dimensions. Since educational researchers have been advocating for practical ways to increase student engagement, substantive effort should be made by revising the three significant aspects 
highlighted in this study; personal, institutional, and external digital technology. The discovery of different factors from this current study can serve as a conceptual framework for future research to explore and test the affecting factors as mentioned in the recommendation to achieve an optimal online learning environment that fosters effective online engagement.

\section{References}

Banna, J., Lin, M. F. G., Stewart, M., \& Fialkowski, M. K. (2015). Interaction matters: Strategies to promote engaged learning in an online introductory nutrition course. Journal of Online Learning and Teaching/MERLOT, 11(2), 249.

Brown, M., Hughes, H., Keppell, M., Hard, N., \& Smith, L. (2015). Stories from students in their first semester of distance learning. The International Review of Research in Open and Distributed Learning, 16(4). https://doi.org/10.19173/irrodl.v16i4.1647

Buck, S. (2016). In Their Own Voices: Study Habits of Distance Education Students. Journal of Library \& Information Services in Distance Learning, 10(3-4), 137-173. https://doi.org/10.1080/1533290x.2016.1206781

Chen, B., Bastedo, K., \& Howard, W. (2018). Exploring Best Practices for Online STEM Courses: Active Learning, Interaction \& Assessment Design. Online Learning, 22(2). https://doi.org/10.24059/olj.v22i2.1369

Chung, E., Noor, N. M., \& Mathew, V. N. (2020). Are you ready? An assessment of online learning readiness among university students. International Journal of Academic Research in Progressive Education and Development, 9(1), 301-317. https://doi.org/10.6007/IJARPED/v9-i4/8177

Deschaine, M. E., \& Whale, D. E. (2017). Increasing student engagement in online educational leadership courses. Journal of Educators Online, 14(1), n1.

Douglas, T., Mather, C., Murray, S., Earwaker, L., James, A., Pittaway, J., Robards, B., \& Salter, S. (2015). A comparison of undergraduate student experiences of assessed versus nonassessed participation in online asynchronous discussion groups: Lessons from a cross disciplinary study in health and sociology. In ASCILITE 2015 (pp. 424-428).

Dushkevych, M., Barabashchuk, H., \& Hutsuliak, N. (2020). Peculiarities of student distance learning in emergency situation condition. Revista Romaneasca Pentru Educatie Multidimensionala, 12(1Sup2), 71-77. https://doi.org/10.18662/rrem/12.1sup2/248

Everson, M., Gundlach, E., \& Miller, J. (2013). Social media and the introductory statistics course. Computers in Human Behavior, 29(5), A69-A81. https://doi.org/10.1016/j.chb.2012.12.033

Farrell, O., \& Brunton, J. (2020). A balancing act: a window into online student engagement experiences. International Journal of Educational Technology in Higher Education, 17(1). https://doi.org/10.1186/s41239-020-00199-x

Gunuc, S., \& Kuzu, A. (2014). Student engagement scale: development, reliability and validity. Assessment \& Evaluation in Higher Education, 40(4), 587-610. https://doi.org/10.1080/02602938.2014.938019

Hammill, J., Nguyen, T., \& Henderson, F. (2020). Student engagement: The impact of positive psychology interventions on students. Active Learning in Higher Education, 146978742095058. https://doi.org/10.1177/1469787420950589

Huwiler, A. G. (2015). Library services for distance students: Opportunities and challenges. Journal of Library \& Information Services in Distance Learning, 9(4), 275-288. https://doi.org/10.1080/1533290x.2015.1111283

Kahu, E. R., Picton, C., \& Nelson, K. (2019). Pathways to engagement: a longitudinal study of the first-year student experience in the educational interface. Higher Education, 79(4), 657-673. https://doi.org/10.1007/s10734-019-00429-w

King, S. B. (2014). Graduate student perceptions of the use of online course tools to support engagement. International Journal for the Scholarship of Teaching and Learning, 8(1). https://doi.org/10.20429/ijsotl.2014.080105

Kumar, S., \& Heathcock, K. (2016). Information literacy support for online students in higher education. Professional Development and Workplace Learning, 1380-1396. https://doi.org/10.4018/978-1-4666-8632-8.ch075

Law, M. Y. (2021). Student's attitude and satisfaction towards transformative learning: A research study on emergency remote learning in tertiary education. Creative Education, 12(3), 494-528. https://doi.org/10.4236/ce.2021.123035

Lee, E., \& Hannafin, M. J. (2016). A design framework for enhancing engagement in student-centered learning: Own it, learn it, and share it. Educational Technology Research and Development, 64(4), 707-734. https://doi.org/10.1007/s11423-015-9422-5

Liu, J., \& Zhang, P. (2020, March). How to initiate a discussion thread?: Exploring factors influencing engagement level of online deliberation. In International Conference on Information (pp. 220-226). Springer, Cham. 
https://doi.org/10.1007/978-3-030-43687-2_17

Martin, F., \& Bolliger, D. U. (2018). Engagement matters: Student perceptions on the importance of engagement strategies in the online learning environment. Online Learning, 22(1). https://doi.org/10.24059/olj.v22i1.1092

Martin, F., \& Ertzberger, J. (2015). Effects of reflection type in the here and now mobile learning environment. British Journal of Educational Technology, 47(5), 932-944. https://doi.org/10.1111/bjet.12327

Martin, F., Wang, C., \& Sadaf, A. (2018). Student perception of helpfulness of facilitation strategies that enhance instructor presence, connectedness, engagement and learning in online courses. The Internet and Higher Education, 37, 52-65. https://doi.org/10.1016/j.iheduc.2018.01.003

Muir, T., Milthorpe, N., Stone, C., Dyment, J., Freeman, E., \& Hopwood, B. (2019). Chronicling engagement: Students' experience of online learning over time. Distance Education, 40(2), 262-277. https://doi.org/10.1080/01587919.2019.1600367

O’ Shea, S., Stone, C., \& Delahunty, J. (2015). “I 'feel' like I am at university even though I am online.” Exploring how students narrate their engagement with higher education institutions in an online learning environment. Distance Education, 36(1), 41-58. https://doi.org/10.1080/01587919.2015.1019970

Pathak, B. K. (2016). Emerging online educational models and the transformation of traditional universities. Electronic Markets, 26(4), 315-321. https://doi.org/10.1007/s12525-016-0223-4

Paul, N. (2018). Developing Elementary Students'Motivation for Online Discussions and Argument-Counterargument Integration Skills in Blended Classrooms (Doctoral dissertation, The Ohio State University).

Phirangee, K., \& Malec, A. (2017). Othering in online learning: an examination of social presence, identity, and sense of community. Distance Education, 38(2), 160-172. https://doi.org/10.1080/01587919.2017.1322457

Purarjomandlangrudi, A., \& Chen, D. (2020). Exploring the influence of learners' personal traits and perceived course characteristics on online interaction and engagement. Educational Technology Research and Development. https://doi.org/10.1007/s11423-020-09792-3

Redmond, P., Heffernan, A., Abawi, L., Brown, A., \& Henderson, R. (2018). An online engagement framework for higher education. Online Learning, 22(1). https://doi.org/10.24059/olj.v22i1.1175

Singh, V., \& Thurman, A. (2019). How Many Ways Can We Define Online Learning? A systematic literature review of definitions of online learning (1988-2018). American Journal of Distance Education, 33(4), 289-306. https://doi.org/10.1080/08923647.2019.1663082

Stone, C., \& O'Shea, S. (2019). Older, online and first: Recommendations for retention and success. Australasian Journal of Educational Technology, 35(1). https://doi.org/10.14742/ajet.3913

Thomas, G., \& Thorpe, S. (2018). Enhancing the facilitation of online groups in higher education: A review of the literature on face-to-face and online group-facilitation. Interactive Learning Environments, 27(1), 62-71. https://doi.org/10.1080/10494820.2018.1451897

Wang, L., \& Sui, J. (2020). Correlation analysis between emotional engagement and achievement of university students in online learning based on an elective course. In Transactions on Edutainment XVI (pp. 13-24). Springer, Berlin, Heidelberg. https://doi.org/10.1007/978-3-662-61510-2_2

Watkins, R. (2014). Developing e-learning activities. Distance Learning, 11(4), 62.

\section{Copyrights}

Copyright for this article is retained by the author(s), with first publication rights granted to the journal.

This is an open-access article distributed under the terms and conditions of the Creative Commons Attribution license which permits unrestricted use, distribution, and reproduction in any medium, provided the original work is properly cited. 